\title{
Organizational Innovation and Tech Innovation Persistence
}

\author{
Javier Fernando Del Carpio Gallegos ${ }^{1^{*}}$, Aurora Salvador Durand ${ }^{* *}$, Eduardo Soria Gomez ${ }^{1}$
}

\begin{abstract}
In developing economies, little is invested in research and development. Therefore, it is proposed that lower-tech firms develop their absorptive capacity and be linked through market and institutional networks to achieve technological innovation persistence. This study uses an ordinal logistics model applied to a sample of Peruvian manufacturing firms, concluding that there is an effect on product and process innovation persistence. Thus, executives can emphasize organizational innovation and absorptive capacity as means to achieve product innovation in developing countries. Moreover, firms should to prioritize the relationships with the market and institutions to achieve a better good or service.
\end{abstract}

Keywords: innovation persistence; low and medium-low technological intensity; absorptive capacity; market networks; institutional networks; manufacturing firms; developing countries; research and development.

Submitted: August $3^{\text {rd }}, 2020 /$ Approved: October $10^{\text {th }}, 2020$

\section{Introduction}

Manufacturing firms face the obligation to develop their innovation capacity and, in this way, to improve their performance (Iandolo \& Ferragina, 2019) or develop competitive advantages (Aziz \& Samad, 2016). For lower-tech manufacturing firms, this need becomes even more apparent, as they invest relatively little in research and development (Maietta, 2015). This study focuses on the behavior of lowertech manufacturing firms in an emerging economy (the Peruvian economy). In this setting, these firms persistently carry out technological innovation, as this type of innovation contributes to a significant percentage of the gross domestic product and to job creation (Del Carpio \& Miralles, 2019).

The literature review indicates that most research has been oriented toward analyzing firms with higher levels of technological intensity in developed economies (Juliao-Rossi \& Schmutzler, 2016), there being little interest in studying the innovative behavior of lower-tech firms in less developed economies (Hervas-Oliver et al., 2011). In particular, it is desirable to study technological innovation persistence, as the results regarding this phenomenon have been ambiguous: some authors indicate that the idea of innovation persistence is spurious (Raymond et al., 2010), while others have stated that there are indeed firms that persistently carry out technological innovations (Le Bas et al., 2015).

Also, this study emphasizes how firms connect with market networks, which are constituted of customers, suppliers, and competitors. Indeed, Triguero and Córcoles (2013) indicate that when firms connect with their suppliers, they are able to incorporate technology into their products and that when firms connect with their customers, they are able to obtain knowledge that helps them to improve their innovation capability and carry out persistent innovation. Also, if firms connect with institutional networks made up of universities and research centers, as explained by Le Bas et al. (2015), they will be able to acquire scientific and technological knowledge that helps them to carry out persistent process innovations.

This study contributes to the literature on innovation carried out by low-tech firms in emerging economies (Del Carpio \& Miralles, 2018), keeping in mind that most studies of on high-tech firms have been carried out in developed economies. A second contribution is related to how the absorptive capacity influences technological innovation persistence, keeping in mind that low-tech firms invest very little in research and development, which in many cases is a fundamental element in the development of absorptive capacity; however, it can be appreciated that, although manufacturing firms in emerging economies do not possess the financial resources to carry out innovation activities, they make an effort to develop technological innovations through the application of inbound open innovation. This was indicated by Spithoven et al. (2010), who specify that firms that do not carry out research and development efforts apply inbound open innovation, which translates into seeking out external knowledge, linking to market and institutional networks to improve their absorptive capacity.

The structure of this study is as follows: after this introduction come the theoretical framework and the formulation of the hypotheses. The third section is about the methodology, describing the data, the definition of the study's variables, and the statistical procedures that have been applied to the data. The fourth section shows the results, and then the fifth section presents the discussion of the results, indicating the theoretical and practical implications, the limitations of the study, and suggested future lines of research. Finally, the conclusions and references are presented.

(1) Facultad de Ingeniería. Universidad ESAN, Perú.

(2) Instituto Nacional de Defensa de la Competencia y de la Protección de la Propiedad Intelectual (INDECOPI), Perú

${ }^{*}$ Corresponding author: jdelcarpio@esan.edu.pe

${ }^{* *}$ Las opiniones expresadas en este documento no representan necesariamente las del Instituto Nacional de Defensa de la Competencia y Protección de la Propiedad Intelectual.

ISSN: 0718-2724. (http://jotmi.org)

Journal of Technology Management \& Innovation @ Universidad Alberto Hurtado, Facultad de Economía y Negocios. 


\section{Theoretical framework and hypotheses}

Technological innovation persistence has motivated the dedication of many researchers who have focused on defining it, like Ganter and Hecker (2013), who indicate that innovation persistence is the innovative behavior of those firms that have carried out innovations in the past, are carrying out innovations in the present, and will carry out innovations in the future. Other researchers have dedicated themselves to analyzing its consequences: in some cases innovation persistence favorably impacts firm profitability (Le Bas \& Poussing, 2014). Along these lines, Tavassoli and Karlsson (2015) indicate that innovation persistence improves firm innovation performance. In other cases, its causes are analyzed: some authors indicate that persistence is due to the sunk cost effect regarding resources oriented toward research and development activities (Guarascio \& Tamagni, 2019), while others consider it an effect of the process of the accumulation of knowledge inside the firm (Scaringella, 2016). The present study will focus on determining how low- and mediumlow-tech firms carry out organizational innovations to foment technological innovation and how firms linked into market or institutional networks improve their ability to develop technological innovations.

The relationship between organizational innovation and technological innovation persistence in low-and medium-low-tech firms

The relationship between organizational innovation and technological innovation persistence in low- and medium-low-tech firms has been researched in different contexts. More research has been done in developed countries (Juliao-Rossi \& Schmutzler, 2016), but research has also been carried out in the Latin American context.

For example, one important study was carried out by Haned and Nguyen-Thi (2014), who analyzed French communitarian innovation surveys and found that innovators that simultaneously carry out product and process innovations are more greatly influenced by the carrying out of organizational innovations. Also, Le Bas et al. (2015) analyzed non-persistent, sporadically persistent, and persistent innovation behavior carried out by more than 28 firms in Luxembourg, finding a positive relationship between organizational innovation and technological innovation persistence. Similarly, Chowhan et al. (2017) studied Canadian firms that participated in the Workplace and Employee Survey in 2006 and found that firms that carried out human resource management projects to improve their organizational methods were more likely to carry out product and process innovations persistently.

In the Latin American context, Suárez (2014) studied close to 800 Argentine firms between 1998 and 2002, which was an unstable period for the Argentine economy, and verified innovation persistence in said context. Additionally, Juliao-Rossi and Schmutzler (2016), studying Colombian manufacturing firms, have verified that product innovation is persistent based on the degree of novelty, especially in one of two cases: when the product innovation is new to the firm or when it is new to that country's internal market.
It can be appreciated that, in various contexts, the firms that carry out organizational innovations are more able to carry out technological innovations persistently, which allows the following hypotheses to be proposed.

H1a: Organizational innovation is related to product innovation persistence in low- and medium-low-tech firms.

H1b: Organizational innovation is related to process innovation persistence in low- and medium-low-tech firms.

The relationship between absorptive capacity and technological innovation persistence in low-and medium-low-tech firms

The relationship between absorptive capacity and technological innovation persistence has been studied from different perspectives. Lööf and Nabavi (2013), analyzing more than 9000 Swedish manufacturing firms with more than 10 employees between 1997 and 2008 found that firms that developed their absorptive capacity to a greater degree, taking advantage of external knowledge, were better able to develop technological innovations, which allowed them to achieve higher levels of productivity. Also, Corradini et al. (2016) analyzed more than 300 small businesses in the United Kingdom that are considered persistent innovators and found that technological diversification allowed the firms to develop their absorptive capacity, permitting them to explore new opportunities in their surroundings, which led them to improve their innovation capability. Moreover, Tavassoli and Karlsson (2015) analyzed five communitarian innovation surveys carried out in Sweden between 2002 and 2012, studying the behavior of firms that presented persistent innovative behavior, and found that absorptive capacity developed in a persistent way improved the ability of firms to accumulate external knowledge, which favored the development of persistent product innovation, as trained human capital favors the development of product and organizational innovation persistence, and also that investment in machinery and equipment had a positive impact on process innovation persistence.

Along these lines, Chowhan et al. (2017) found that firms that hired qualified personnel or trained their personnel developed absorptive capacity, which helped them to process external knowledge to assimilate it and improve their innovation capability. Also, Chowhan et al. (2017) found a positive relationship between practices to improve absorptive capacity of employees and persistent innovation in the firm. On the other hand, Mothe \& Nguyen-Thi (2017) conducted an empirical analysis of French firms and found that those that developed the ability to assimilate and exploit external knowledge had better innovation performance. In the same way, they found that absorptive capacity moderated the impact of the persistent search for knowledge that led the firm to carry out innovations.

H2a: Absorptive capacity is related to product innovation persistence in low- and medium-low-tech firms.

$\mathrm{H} 2 \mathrm{~b}$ : Absorptive capacity is related to process innovation persistence in low- and medium-low-tech firms. 
The relationship between market networks and technological innovation persistence in low-and medium-low-tech firms

The literature review presents several studies that show that firms that connect with customers, suppliers, competitors, consultants, and headquarters develop product innovations, as indicated by Piercy (2009), connect with suppliers not only to reduce costs but also to promote process innovation. Furthermore, Triguero \& Córcoles (2013), who analyzed the information provided by the Survey on Business Strategies, which covers the period of 1990 to 2008, found that Spanish firms that developed strong relationship with their suppliers were able to incorporate technology into their products and that by developing strong relationships with their customers, they were able to obtain knowledge that helped them to improve their innovation capability and persistently carry out innovations.

Later, Haned et al. (2014), analyzing French communitarian innovation surveys, found that firms that developed the ability to connect with customers were better able to develop innovations. Along these lines, Le Bas et al. (2015) found that cooperation with customers and suppliers made it easier to introduce products onto the market, as they provide information about the customer needs and trends in the market. Ghauri et al. (2016) argue that the development of the ability to connect through networks facilitates the development of product innovations. Also, Badillo \& Moreno (2016), who analyzed Spanish firms that participated in the Panel Technological Panel between 2002 and 2010, found that firms that persistently collaborated with customers, suppliers, and competitors were better able to develop innovations persistently.

Thus, based on the aforementioned arguments, the following hypotheses are proposed:

H3a: Market networks are related to product innovation persistence in low- and medium-low-tech firms.

H3b: Market networks are related to process innovation persistence in low- and medium-low-tech firms.

The relationship between institutional networks and technological innovation persistence in low-and medium-low-tech firms

Institutional networks made up of universities, public research institutes, and private research institutes favor the development of product innovation. The literature review presents many studies that give evidence of this relationship. For example, Tether and Tajar (2008) indicate that private research institutes play an important role in the development of product innovations. Also, Un et al. (2010) found that firms that sought out connections with universities achieved a higher percentage of sales of new products than firms that were connected with other institutions. Along these same lines, Ganter and Hecker
(2013), who studied the results of the fourth, fifth, and sixth communitarian innovation surveys carried out in Germany, found that firms that tried to collaborate with universities or suppliers were the most successful in exploiting external knowledge, which favored the carrying out of innovative projects, reflected in greater technological and organizational innovation persistence.

Le Bas et al. (2015) can also be mentioned. They found that cooperation with universities and research institutes allowed them to have access to scientific and technological knowledge that helped them in the process of acquiring new machinery and equipment, which made persistent process innovation easier. Also, Mothe \& Nguyen-Thi (2017) found that firms that collaborated with universities and public research institutes developed more absorptive capacity and were more able to develop persistent innovations. Furthermore, HewittDundas et al. (2019), who analyzed the research activities of more than 130 universities in the United Kingdom and especially the relationship between universities and businesses, found that firms that connected with universities as a source of knowledge or to carry out technology transfer projects were more likely to develop persistent product innovations.

Based on these arguments, the following hypotheses can be proposed:

H4a: Institutional networks are related to product innovation persistence in low- and medium-low-tech firms.

H4b: Institutional networks are related to process innovation persistence in low- and medium-low-tech firms.

\section{Methodology}

\section{Data}

This study uses data from the 2012 and 2015 National Survey of the Manufacturing Industry. These surveys targeted Peruvian manufacturing firms to obtain knowledge about their innovation processes and were carried out by the Ministry of Economics and Finance (MEF); the National Science, Technology, and Technological Innovation Council (Concytec); and the National Statistics and Informatics Institute (INEI). They were designed based on the methodological framework of the Bogota Manual, which allows comparable indicators to be developed so that that the results across countries in the Latin American region can be compared. The data collection (INEI Questionnaire, 2012; INEI Questionnaire, 2015) was carried out over a reference period of 2009-2011 and 2012-2014, leading to a representative sample of 1220 and 1452 firms, respectively. These firms were of large, medium, and small size and were located in different regions of the country. However, for the purposes of this study, 271 low- and medium-low-tech manufacturing firms that were surveyed in both 2012 and 2015 are analyzed. Table 1 shows some statistics regarding the number of firms according to their technological intensity, age, and size. 
Table 1: Number of firms according to technological intensity, age, and size.

\begin{tabular}{lll}
\hline Technological Intensity & Number & Relative frequency \\
\hline Low & 162 & $60 \%$ \\
\hline Medium-low & 109 & $40 \%$ \\
Total & 271 & \\
\hline Firm age & & $20 \%$ \\
\hline Old ( $\geq 44$ years old) & 53 & $61 \%$ \\
Young ( 25 years old) & 167 & $19 \%$ \\
Middling (between 26 and 43 years old) & 51 & \\
Total & 271 & $14 \%$ \\
\hline Firm size & & $34 \%$ \\
\hline Small (50 employees) & 39 & $52 \%$ \\
Medium (51 to 250 employees) & 91 & 141 \\
\hline Large ( $\geq 251$ employees) & 271 & \\
\hline Total
\end{tabular}

Source: INEI 2012 and 2015

\section{Measurement of the variables}

Dependent variables.

The dependent variables are "process innovation persistence" and "product innovation persistence." The INEI database contains two items related to process innovation: 1) introduction of a new process and 2) introduction of a significantly improved process, and four items related to product innovation: 1) introduction of a new good, 2) introduction of a new service, 3) introduction of a significantly improved good, and 4) introduction of a significantly improved service. According to Le Bas et al. (2015), to measure process and product innovation persistence, yes/no answers to items related to process and product innovation are used. In this sense, the variable takes on a value of 0 , "non-recurring innovator," if the firm did not carry out any type of innovation in 2012 or in 2015; it takes on a value of 1 , "sporadic innovator," if the firm carried out some type of innovation in one of those years-that is, either in 2012 or in 2015; and it takes on a value of 2, "persistent innovator," if the firm carried out some type of innovation in both years

\section{Independent variables}

In the first place, "organizational innovation persistence" is used. The survey has three items related to organizational innovation: 1) Work organization, 2) External relationships with other firms or public institutions, and 3) Design or packaging of the good or service. To measure organizational innovation persistence, the yes/no answers to items related to organizational innovation are used. In this sense, the variable takes on a value of 0 , "non-recurring innovator," if the firm did not carry out any type of innovation in 2012 or in 2015; it takes on a value of 1 , "sporadic innovator," if the firm carried out some type of innovation in one of the years-that is, either in 2012 or in 2015; and it takes on a value of 2, "persistent innovator," if the firm carried out some type of innovation in both years, according to the classification used by Le Bas et al. (2015) to define the innovation profiles.
In the second place, absorptive capacity (ACAP) is used, which is a factorial of the following items: 1) Logarithm of research and development expenses, 2) Logarithm of expenditures on training for innovation activities, and 3) A dichotomous variable: whether or not the firm has a technological research and development department, according to Escribano et al. (2009) and Rammer et al. (2009).

In the third place, institutional networks are used, which are a factorial of the following items: 1) If the firm is connected with universities, 2) If the firm is connected with public research institutes, and 3) If the firm is connected with private research institutes. Finally, market networks are used as a factorial of the following items: 1) Connections with suppliers, 2) Connections with customers, 3) Connection with competitors or other firms, and 4) Connection with consultants and experts, according to the criteria established by Laursen and Salter $(2004,2006)$.

\section{Control variables}

Firm size, expressed as a logarithm of the number of employees in the firm, (Schoenmakers \& Duysters, 2006; Laursen \& Salter, 2006) is used as a control variable, as is firm age, expressed as a logarithm of years the firm had been in operation up until 2014, according to Thornhill (2006).

\section{Analytical method}

To respond to the proposed research questions, a logit ordinal model was estimated, because both dependent variables were measured on an ordinal scale. The multinomial logistics model (MLM) would not take into account the ordinal nature of the results; therefore, the odds rations estimated would not be able to be interpreted correctly in the analysis (Hosmer \& Lemeshow, 2000). For this reason, it was decided that an ordinal logistics model (OLM) be used, as this type of model takes the order of the classification of the results into consideration, 
in terms of accumulated logits, maintaining the hypothesis of proportional probabilities (Zwan et al., 2007). This is the equivalent of saying that the effect of each independent variable is the same for all of the relative accumulated probabilities.

In this study, the model assumes that the dependent variable is a latent variable, which is associated with a set of independent variables:

$$
\mathrm{y}^{*}=\beta_{1} \mathrm{X}_{1 \mathrm{i}}+\beta_{2} \mathrm{X}_{2 \mathrm{i}}+\cdots+\beta_{3} \mathrm{X}_{\mathrm{ki}}+\varepsilon_{\mathrm{i}}
$$

In this case, the latent variable $y^{\star}$ is firms' product or process innovation persistence; however, the variable " $y$ " can be classified as an ordinal variable that takes on three possible values: $0=$ non-recurring innovator, $1=$ sporadic innovator, and $2=$ persistent innovator. Then, the variable " $y$ " can take on any of these values, according to the following rule (Greene, 2012):

$$
\begin{aligned}
& y=0 \text { if } y^{*} \leq \alpha_{1}=\beta_{1} X_{1 i}+\cdots+\beta_{k} X_{k i}+\varepsilon_{i} \leq \alpha_{1} \\
& y=1 \text { if } \alpha_{1}<y^{*} \leq \alpha_{2}=\alpha_{1}<\beta_{1} X_{1 i}+\cdots+\beta_{k} X_{k i}+\varepsilon_{i} \leq \alpha_{2} \\
& y=2 \text { if } \alpha_{2}<y^{*} \leq \alpha_{2}=\alpha_{2}<\beta_{1} X_{1 i}+\cdots+\beta_{k} X_{k i}+\varepsilon_{i}
\end{aligned}
$$

The predetermined probability for each category is the following:

$$
\begin{aligned}
& P(y=0 \backslash X)=P\left(y^{*} \leq \alpha_{1}\right)=P\left(\beta_{1} X_{1 i}+\cdots+\beta_{k} X_{k i}+\varepsilon_{i} \leq \alpha_{1}\right) \\
& P(y=1 \backslash X)=P\left(\alpha_{1}<y^{*} \leq \alpha_{2}\right)=P\left(\alpha_{1}<\beta_{1} X_{1 i}+\cdots+\beta_{k} X_{k i}+\varepsilon_{i} \leq \alpha_{2}\right) \\
& P(y=2 \backslash X)=P\left(\alpha_{2}<y^{*} \leq \alpha_{2}\right)=P\left(\alpha_{2}<\beta_{1} X_{1 i}+\cdots+\beta_{k} X_{k i}+\varepsilon_{i}\right)
\end{aligned}
$$

According to Agresti (2007), the accumulated probability that $y$ is the probability that $y$ can be found at or under a certain point in particular. For the category of result $j$, the accumulated probability is as follows:

$$
[P(y \leq j)]=\frac{\exp \left(\alpha_{j}+X_{i} \beta\right)}{1+\exp \left(\alpha_{j}+X_{i} \beta\right)}, \quad j=1, \ldots, J-1
$$

Finally, the equation that is estimated for each type of innovation persistence, taking into consideration the fact that it follows a logistic distribution, is the following:

$$
\ln \left(y_{j}\right)=\ln \left(\begin{array}{c}
\pi_{j}(x) \\
1-\pi_{j}(x)
\end{array}\right)=\alpha_{j}+\beta_{1} X_{1 i}+\cdots+\beta_{k} X_{k i}+\varepsilon_{i}
$$

\section{Results}

Tables 2 and 3 present the descriptive statistics for innovation persistence in low- and medium-low-tech firms. Moreover, the Bonferroni test was applied to analyze if the differences between non-recurring, sporadic, and persistent innovators are significant. Regarding process innovation persistence, it can be observed that 31 firms are non-recurring innovators (11.44\%), 154 firms are sporadic innovators (56.83\%), and 86 firms are persistent innovators (31.73\%), and, regarding product innovation persistence, it can be observed that 41 firms are non-recurring innovators (15.13\%), 105 firms are sporadic innovators (38.75\%), and 125 firms are persistent innovators $(46.13 \%)$. Moreover, the variation in the frequency of innovation persistence according to different characteristics is presented. Fully $68.60 \%$ of firms that are persistent process innovators are also persistent organizational innovators, and $19.35 \%$ of firms that are nonrecurring process innovators were persistent in terms of carrying out organizational innovation. In the same way, it can be observed that, regarding product innovation persistence, 59.20\% of firms that are persistent innovators in terms of product innovation are also persistent in terms of organizational innovation, while $26.67 \%$ of firms that are sporadic product innovators carry out organizational innovations persistently, and $24.39 \%$ of firms that are non-recurring product innovators were persistent in terms of organizational innovation. Moreover, for process innovation persistence, significant differences can be observed for the following

\begin{tabular}{|c|c|c|c|c|}
\hline & \multicolumn{4}{|c|}{ Process innovation persistence } \\
\hline & Non-Recurring Innovator $(n=31)$ & Sporadic Innovator $(n=154)$ & Persistent Innovator $(\mathrm{n}=\mathbf{8 6})$ & Difference \\
\hline \multicolumn{5}{|c|}{ Organizational Innovation Persistence } \\
\hline Non-Recurring Innovator & $25.81 \%$ & $20.78 \%$ & $9.30 \%$ & * \\
\hline Sporadic Innovator & $54.84 \%$ & $48.70 \%$ & $22.09 \%$ & $* * *$ \\
\hline Persistent Innovator & $19.35 \%$ & $30.52 \%$ & $68.60 \%$ & $* * *$ \\
\hline ACAP & -0.29 & -0.13 & 0.33 & $* * *$ \\
\hline Institutional Networks & -0.19 & -0.09 & 0.22 & $* *$ \\
\hline Market Networks & -0.23 & 0.02 & 0.05 & n.s.d. \\
\hline Age & 2.81 & 3.12 & 3.13 & * \\
\hline Size & 4.97 & 5.54 & 5.69 & + \\
\hline
\end{tabular}
variables: ACAP, institutional networks, age, and size. These variables occurred to a greater degree when the firms carried out innovations persistently. Finally, for product innovation persistence, significant differences can be observed for the variables ACAP, institutional networks, market networks, and size, which, similarly to the previous case, have a higher mean value when firms carry out innovations persistently.

Table 2: Descriptive statistics regarding process innovation persistence

Process innovation persistence

Note: ${ }^{* * *} \mathrm{p}<0,01,{ }^{* *} \mathrm{p}<0,05,{ }^{\star} \mathrm{p}<0,1$ (Bonferroni test)

n.s.d.: no significant difference

Source: STATA software, the authors' calculations. 
Product innovation persistence

Non-Recurring Innovator ( $n=31)$ Sporadic Innovator $(n=154)$

Persistent Innovator $(\mathbf{n}=\mathbf{8 6})$

\author{
Organizational Innovation Persistence \\ Non-Recurring Innovator \\ Sporadic Innovator \\ Persistent Innovator
}

$19.51 \%$

$56.10 \%$

$24.39 \%$

$-0.45$

ACAP

Institutional Networks

$-0.02$

$-0.21$

3.06

5.56
Age

Size

\begin{abstract}
$25.71 \%$
$47.62 \%$

$26.67 \%$
\end{abstract}

$-0.31$

$-0.17$

$-0.03$

3.03

5.24

\section{$10.40 \%$ \\ $30.40 \%$ \\ $59.20 \%$}

0.41

0.15

0.09

3.15

n.s.d.

Note: ${ }^{* *} \mathrm{p}<0,01,{ }^{* *} \mathrm{p}<0,05,{ }^{*} \mathrm{p}<0,1$ (Bonferroni test)

n.s.d.: no significant difference

Source: STATA software, the authors' calculations.

Table 4 presents the marginal effects of process and product innovation persistence on low- and medium-low-tech firms. As for the results regarding process innovation persistence, it can be observed that, when compared with being a non-recurring innovator in terms of organizational innovation (base category), being a persistent innovator in terms of organizational innovation lessened the probability of belonging to the first category (non-recurring process innovator) by $0.09 \mathrm{pp}$. at a $0.1 \%$ significance level, diminished the probability of belonging to the second category (sporadic process innovator) by $0.15 \mathrm{pp}$. at a $0.1 \%$ significance level, and increased the probability of belonging to the third category (persistent process innovator) by $0.25 \mathrm{pp}$. at a $0.1 \%$ significance level. As for absorptive capacity (ACAP), when the firm possessed a better absorptive capacity indicator, the probability of belonging to the third category (persistent innovator) increased by $0.09 \mathrm{pp}$. at a $1 \%$ significance level. The same happened when the firm had a better indicator for institutional networks: the probability of belonging to the third category (persistent innovator) increased by $0.08 \mathrm{pp}$. at a $5 \%$ significance level.
As for the results regarding product innovation persistence, it can be observed that, when compared with being a non-recurring innovator in terms of organizational innovation (base category), being a persistent product innovator in terms of organizational innovation lessened the probability of belonging to the second category (sporadic product innovator) by $0.19 \mathrm{pp}$. at a $0.5 \%$ significance level and increased the probability of belonging to the third category (persistent product innovator) by $0.19 \mathrm{pp}$. at a $0.5 \%$ significance level. As for absorptive capacity (ACAP), when the firm possessed a better absorptive capacity indicator, the probability of belonging to the third category (persistent innovator) increased by $0.25 \mathrm{pp}$. at a $0.01 \%$ significance level. The same happened when the firm had a better indicator for institutional networks: the probability of belonging to the third category (persistent innovator) increased by $0.08 \mathrm{pp}$. at a $5 \%$ significance level, and when the firm had a better indicator for market networks, the probability of belonging to the third category (persistent innovator) increased by $0.05 \mathrm{pp}$. at a $10 \%$ significance level. 
Table 4: Marginal Effects of process and product innovation persistence

\begin{tabular}{|c|c|c|c|c|c|c|}
\hline $\begin{array}{l}\text { Persistence } \\
\text { according to type } \\
\text { of innovation }\end{array}$ & \multicolumn{3}{|c|}{ Process } & \multicolumn{2}{|c|}{ Product } & $\begin{array}{l}\text { Persistent } \\
\text { Innovator }\end{array}$ \\
\hline \multicolumn{7}{|c|}{ Organizational Innovation Persistence } \\
\hline Sporadic Innovator & 0.02 & 0.00 & -0.02 & 0.05 & -0.04 & -0.01 \\
\hline Persistent Innovator & $(0.04)$ & $(0.05)$ & $(0.07)$ & $(0.06)$ & $(0.08)$ & $(0.08)$ \\
\hline \multirow[t]{2}{*}{ ACAP } & $-0.05^{*}$ & $-0.04^{*}$ & $0.09^{* *}$ & $-0.17^{\star * *}$ & $-0.08^{* * *}$ & $0.25^{* * *}$ \\
\hline & $(0.02)$ & $(0.02)$ & $(0.03)$ & $(0.03)$ & $(0.02)$ & $(0.03)$ \\
\hline $\begin{array}{l}\text { Institutional } \\
\text { Networks }\end{array}$ & $-0.04^{*}$ & $-0.04^{*}$ & $0.08^{*}$ & 0.02 & $-0.10^{* *}$ & $0.08^{*}$ \\
\hline Market Networks & $(0.02)$ & $(0.01)$ & $(0.03)$ & $(0.02)$ & $(0.01)$ & $(0.03)$ \\
\hline \multirow[t]{2}{*}{ Age } & -0.01 & -0.01 & 0.03 & -0.01 & -0.00 & 0.02 \\
\hline & $(0.02)$ & $(0.02)$ & $(0.04)$ & $(0.02)$ & $(0.01)$ & $(0.04)$ \\
\hline \multirow[t]{2}{*}{ Size } & 0.00 & 0.00 & -0.00 & 0.02 & 0.01 & -0.02 \\
\hline & $(0.01)$ & $(0.01)$ & $(0.02)$ & $(0.01)$ & $(0.01)$ & $(0.02)$ \\
\hline Number of firms & & 271 & \multicolumn{4}{|c|}{271} \\
\hline
\end{tabular}

\section{Discussion}

The discussion of the results will focus on three aspects: theoretical implications, practical implications, and future lines of research.

\section{Theoretical implications}

This study contributes in various ways to the literature on innovation persistence, especially to the study of innovation persistence in an emerging economy, emphasizing the development of innovations in low- and medium-low-tech firms. As the results indicate, firms that carry out persistent organizational innovations have a higher probability of carrying out process innovations rather than product innovations. These results contradict the results obtained by Le Bas et al. (2015), as in their case, Luxembourgish firms were more likely to carry out product innovations than process innovations. This contradiction is a motive to carry out more studies in the future, to determine why the innovation behavior in the two cases differs.

A second aspect to keep in mind has to do with the impact of absorptive capacity on technological innovation persistence. It can be appreciated that absorptive capacity has a greater influence on product innovation persistence than on process innovation, which corresponds to the results obtained by Tavassoli and Karlsson (2015), but specifying that, taking into account research and development expenses, which is one of the elements that have been taken into account in the present study to measure absorptive capacity. It is important to note that emerging economies invest very little into research and development, but despite this limitation, manufacturing firms in emerging economies have been able to carry out technological innovations.

A third theoretical contribution focuses on the way that interaction with market and institutional networks encourages low- and medium-low-tech firms' technological innovation persistence. In the first place, market networks only weakly impact the development of product innovations, as Badillo and Moreno (2016) also found. As for connections with institutional networks, especially universities, they encourage the development of both product and process innovations; this finding agrees with the literature, which indicates that connections between firms and universities favors the development of process innovations (Le Bas et al., 2015) more than product innovations and that connections with customers, suppliers, and competitors favors the development of product innovations (Ghauri et al., 2016). 


\section{Practical implications}

The present study has practical implications, as well: executives of firms should promote organizational practices that allow for work to be better organized, for external relationships with other firms or public institutions to be enhanced, and for the design or packaging of the good or service to be improved.

It is suggested that executives invest more in research and development, train their employees more to foment innovation activities, and, as much as possible, implement a research and development department in order to develop their ability to exploit external knowledge to improve their technological innovation capacity.

Also, executives should try to connect themselves with market networks in order to obtain valuable information that will allow them to learn what is happening in the market and to provide innovative products that satisfy the needs of their customers. Additionally, they should be encouraged to seek out universities as strategic partners to develop persistent process innovations, which could help them to reduce costs and to be more competitive.

It is also important to indicate that policymakers, in their desire to encourage technological innovation, should orient their resources to improve relationships between firms and universities and research centers so that technology transfer projects can be developed. Additionally, it is recommended that policymakers finance employee training courses for small and medium-sized firms that teach them to develop their innovation capacity and foment those firms' participation in technology fairs to increase their contact with machinery and equipment suppliers, which for medium-sized firms are a source of technological knowledge.

\section{Limitations and future research}

As no study is exempt from limitations, a first limitation is the fact that this study uses a logistic model that does not take into account dynamic situations that manufacturing firms in emerging economies run into. The study uses data published in 2012 and 2015, a time period in which the Peruvian economy was stable. It would be interesting to carry out studies in moments of economic crisis to verify if the firms continue carrying out persistent technological innovations.

A second limitation has to do with the use of data from two national surveys. Generalizations cannot be made; it would be convenient to include the data from at least three national innovation surveys in order to have more reliable results. Moreover, it is suggested that comparative studies be carried out with the data from national surveys conducted in other Latin American countries and, in this way, points of commonality and difference in the diverse innovative behaviors of lower-tech firms in neighboring countries can be found.

An additional limitation is that the national innovation surveys of the Peruvian manufacturing industry carried out in 2012 and 2015 employed a slightly different questionnaire. There were minor changes made to the 2015 survey; these impede using the study variables consistently.

\section{Conclusions}

Using a sample of 271 low- and medium-low-tech manufacturing firms and econometric evidence, this study complements findings from previous studies regarding the effect of organizational innovation, absorptive capacity, market networks, and institutional networks on product and process innovation persistence. The main results show that there is a positive effect on product and process innovation persistence when the firm has also been persistent in its organizational innovation, and this agrees with the findings of other recent studies (Le Bas et al., 2015 \& Haned et al., 2014). That is to say, if a firm carries out organizational innovation persistently, the probability of carrying out product and process innovation increases; however, there is an even bigger effect on process innovation persistence. As for absorptive capacity, it has been found that absorptive capacity increases the probability that a firm will innovate its products and processes persistently. However, it has been found that there is a greater effect on product innovation, along the lines of what Tavassoli and Karlssonv (2015) also identified. Additionally, evidence has been found that market networks increase the probability of carrying out persistent product innovation; no evidence of an effect on process innovation has been identified. Finally, institutional networks increase the probability of carrying out persistent product and process innovation.

\section{References}

Agresti, A. (2007). An introduction to categorical data analysis (2nd ed.). John Wiley \& Sons. doi: 10.1002/sim.3564

Aziz, N. N. A., \& Samad, S. (2016). Innovation and competitive advantage: Moderating effects of firm age in foods manufacturing SMEs in Malaysia. Procedia Economics and Finance, 35(2016), 256-66. doi: 10.1016/s2212-5671(16)00032-0

Badillo, E. R., \& Moreno, R. (2016). Are collaborative agreements in innovation activities persistent at the firm level? Empirical evidence for the Spanish case. Review of Industrial Organization, 49(1), 71-101. doi: 10.1007/s11151-015-9493-9

Chowhan, J., Pries, F., \& Mann, S. (2017). Persistent innovation and the role of human resource management practices, work organization, and strategy. Journal of Management \& Organization, 23(3), 456471. doi: $10.1017 /$ jmo.2016.8

Corradini, C., Demirel, P., \& Battisti, G. (2016). Technological diversification within UK's small serial innovators. Small Business Economics, 47(1), 163-177. doi: 10.1007/s11187-015-9698-1

Del Carpio Gallegos, J. F., \& Miralles Torner, F. (2018). Absorptive capacity and innovation in low-tech companies in emerging economies. Journal of Technology Management \& Innovation, 13(2), 3-11. doi: 10.4067/s0718-27242018000200003 
Del Carpio Gallegos, J. F., \& Miralles, F. (2019). Propensity to the technological innovation of the Peruvian manufacturing companies that do not develop research and development (R\&D) activities. Revista Universidad y Empresa, 21(37), 31-51. doi: 10.12804/revistas. urosario.edu.co/empresa/a.6460

Escribano, A., Fosfuri, A., \& Tribó, J. A. (2009). Managing external knowledge flows: The moderating role of absorptive capacity. Research Policy, 38(1), 96-105. doi:10.1016/j.respol.2008.10.022

Ganter, A., \& Hecker, A. (2013). Persistence of innovation: Discriminating between types of innovation and sources of state dependence. Research Policy, 42(8), 1431-1445. doi: 10.1016/j.respol.2013.04.001

Ghauri, P., Wang, F., Elg, U., \& Rosendo-Ríos, V. (2016). Market driving strategies: Beyond localization. Journal of Business Research, 69(12), 5682-5693. doi: 10.1016/j.jbusres.2016.04.107

Greene, W. (2012). Econometric analysis (7th ed.). Stern School of Business.

Guarascio, D., \& Tamagni, F. (2019). Persistence of innovation and patterns of firm growth. Research Policy, 48(6), 1493-1512. doi: 10.1016/j.respol.2019.03.004

Haned, N., Mothe, C., \& Nguyen-Thi, T. U. (2014). Firm persistence in technological innovation: the relevance of organizational innovation. Economics of Innovation and New Technology, 23(5-6), 490516.

Hervas-Oliver, J. L., Garrigos, J. A., \& Gil-Pechuan, I. (2011). Making sense of innovation by R\&D and non-R\&D innovators in low technology contexts: A forgotten lesson for policymakers. Technovation, 31(9), 427-446. doi: 10.1016/j.technovation.2011.06.006

Hewitt-Dundas, N., Gkypali, A., \& Roper, S. (2019). Does learning from prior collaboration help firms to overcome the 'two-worlds' paradox in university-business collaboration? Research Policy, 48(5), 1310-1322. doi: 10.1016/j.respol.2019.01.016

Hosmer, D. W., \& Lemeshow, S. (2000). Applied logistic regression ( $2^{\text {nd }}$ ed.). John Wiley \& Sons. doi: 10.1002/0471722146

Iandolo, S. and Ferragina, A.M. (2019). Does persistence in internationalization and innovation influence firms' performance? Journal of Economic Studies, 46(7), 1345-1364. doi: 10.1108/JES-04-2019-0152

INEI Questionnaire (2012). Peru: National survey of innovation in manufacturing industry, 2012 - Main results. http://innovacion.enlacesred.org/pdf/peru/Peru_Manufacturera.pdf

INEI Questionnaire (2015). Peru: National survey of innovation in manufacturing industry, 2015 - Main results. https://www.inei.gob. pe/media/MenuRecursivo/publicaciones_digitales/Est/Lib1253/ cap15/cap15.pdf
Juliao-Rossi, J., \& Schmutzler, J. (2016). Persistence in generating and adopting product innovations. Academia Revista Latinoamericana de Administración, 29. 125-146. doi: 10.1108/arla-08-2015-0

Laursen, K., \& Salter, A. (2004). Searching high and low: What types of firms use universities as a source of innovation? Research Policy, 33(8), 1201-1215. doi: 10.1016/j.respol.2004.07.004

Laursen, K., \& Salter, A. (2006). Open for innovation: The role of openness in explaining innovation performance among U.K. manufacturing firms. Strategic Management Journal, 27(2), 131-150. doi: 10.1002/smj.507

Le Bas, C., Mothe, C. \& Nguyen-Thi, T.U. (2015). The differentiated impacts of organizational innovation practices on technological innovation persistence. European Journal of Innovation Management, 18(1), 110-127. doi: 10.1108/ejim-09-2012-0085

Le Bas, C., \& Poussing, N. (2014). Are complex innovators more persistent than single innovators? An empirical analysis of innovation persistence drivers. International Journal of Innovation Management, 18(1), 1450008. doi: 10.1142/s136391961450008x

Lööf, H., \& Nabavi, P. (2013). Increasing returns to smart cities. Regional Science Policy \& Practice, 5(2), 255-262. doi: 10.1111/rsp3.12008

Maietta, O. W. (2015). Determinants of university-firm R\&D collaboration and its impact on innovation: A perspective from a lowtech industry. Research Policy, 44(7), 1341-1359. doi: 10.1016/j.respol.2015.03.006

Mothe, C., \& Nguyen-Thi, U. T. (2017). Persistent openness and environmental innovation: An empirical analysis of French manufacturing firms. Journal of Cleaner Production, 162, S59-S69. doi: 10.1016/j. jclepro.2016.12.063

Piercy, N. F. (2009). Strategic relationships between boundary-spanning functions: Aligning customer relationship management with supplier relationship management. Industrial Marketing Management, 38(8), 857-864. doi: 10.1016/j.indmarman.2009.03.015

Rammer, C., Czarnitzki, D., \& Spielkamp, A. (2009). Innovation success of non-R\&D-performers: substituting technology by management in SMEs. Small Business Economics, 33(1), 35-58. doi: 10.1007/ s11187-009-9185-7

Raymond, W., Mohnen, P., Palm, F., \& Van Der Loeff, S. S. (2010). Persistence of innovation in Dutch manufacturing: Is it spurious? The Review of Economics and Statistics, 92(3), 495-504. doi: 10.1162/ rest_a_00004

Scaringella, L. (2016). Knowledge, knowledge dynamics, and innovation: Exploration of the internationalization of a multinational corporation. European Journal of Innovation Management, 19(3), 337-361. doi: 10.1108/EJIM-05-2015-0031 
Schoenmakers, W., \& Duysters, G. (2006). Learning in strategic technology alliances. Technology Analysis \& Strategic Management, 18(2), 245-264. doi: 10.1080/09537320600624162

Spithoven, A., Clarysse, B., \& Knockaert, M. (2010). Building absorptive capacity to organise inbound open innovation in traditional industries. Technovation, 30(2), 130-141. doi: 10.1016/j.technovation.2009.08.004

Suárez, D. (2014). Persistence of innovation in unstable environments: Continuity and change in the firm's innovative behavior. Research Policy, 43(4), 726-736. doi: 10.1016/j.respol.2013.10.002

Tavassoli, S., \& Karlsson, C. (2015). Persistence of various types of innovation analyzed and explained. Research Policy, 44(10), 1887-1901. doi: 10.1016/j.respol.2015.06.001

Tether, B. S., \& Tajar, A. (2008). Beyond industry-university links: Sourcing knowledge for innovation from consultants, private research organisations and the public science-base. Research Policy, 37(6-7), 1079-1095. doi: 10.1016/j.respol.2008.04.003
Thornhill, S. (2006). Knowledge, innovation and firm performance in high-and low-technology regimes. Journal of Business Venturing, 21(5), 687-703. doi: 10.1016/j.jbusvent.2005.06.001

Thurik, R., Grilo, I., \& van der Zwan, P. (2007). The Entrepreneurial process and its determinants (Summary). Frontiers of Entrepreneurship Research, 27(5), 12.

Triguero, A., \& Córcoles, D. (2013). Understanding innovation: An analysis of persistence for Spanish manufacturing firms. Research Policy, 42(2), 340-352. doi: 10.1016/j.respol.2012.08.003

Un, C. A., Cuervo-Cazurra, A., \& Asakawa, K. (2010). R\&D collaborations and product innovation. Journal of Product Innovation Management, 27(5), 673-689. doi: 10.1111/j.15405885.2010.00744.x 